\section{Interactions of Lysyl-Bradykinin and Antidiuretic Hormone in the Rabbit Cortical Collecting Tubule}

Victor L. Schuster, Juha P. Kokko, and Harry R. Jacobson

Department of Internal Medicine, Division of Nephrology, The

University of Texas Health Science Center, Southwestern Medical School, Dallas, Texas 75235; Department of Internal Medicine,

Nephrology Division, University of Iowa, Iowa City, Iowa 52242
A nins produce diuresis, it is not clear to what extent this response is due to hemodynamically mediated medullary washout and/or to direct epithelial effects of kinins. Recent evidence has shown that bradykinin binds to collecting tubules in vitro. We therefore examined the interactions of lysyl-bradykinin and antidiuretic hormone (ADH) with respect to hydraulic conductivity $\left(L_{\mathrm{p}}\right)$ in the rabbit cortical collecting tubule perfused in vitro. To ensure adequate substrate for prostaglandin synthesis, the bath contained $2.5 \mu \mathrm{M}$ arachidonic acid. Arachidonic acid produced no change in base-line $L_{\mathrm{p}}$ and had no effect on the subsequent response to a supramaximal dose of $\mathrm{ADH}(100 \mu \mathrm{U} / \mathrm{ml})$. Therefore, all subsequent experiments were done in the presence of arachidonic acid. Lysyl-bradykinin $\left(10^{-9} \mathrm{M}\right)$ added to either the lumen or bath had no effect on baseline $L_{\mathrm{p}}$. Collecting tubules which were exposed for $1 \mathrm{~h}$ to bath lysyl-bradykinin $\left(10^{-9} \mathrm{M}\right)$ had a significantly diminished subsequent $L_{\mathrm{p}}$ in response to ADH $(P<0.02)$. In tubules exposed to bath lysyl-bradykinin plus indomethacin $(5 \mu \mathrm{M})$, the subsequent ADH response was normal. Lysyl-bradykinin $\left(10^{-9} \mathrm{M}\right)$ added to the lumen had no effect on subsequent $\mathrm{ADH}$ response.

We conclude that lysyl-bradykinin from the basolateral side inhibits the hydroosmotic response of the cortical collecting tubule to $\mathrm{ADH}$, and that this inhibition is probably prostaglandin-mediated. Lysyl-bradykinin does not affect water flow from the luminal surface. These

Dr. Schuster was a Roche Fellow of the National Kidney Foundation during part of this work. Please address correspondence to Dr. Jacobson, Department of Internal Medicine, University of Texas Science Center, Dallas, TX 75235.

Received for publication 29 September 1983 and in revised form 1 March 1984

J. Clin. Invest.

(C) The American Society for Clinical Investigation, Inc.

$0021-9738 / 84 / 06 / 1659 / 09 \quad \$ 1.00$

Volume 73, June 1984, 1659-1667 data indicate that the diuresis seen with kinin infusions may result, at least in part, from a direct epithelial effect. They also suggest a role of the renal kallikrein-kinin system in modulating water transport in vivo.

\section{Introduction}

The exact physiologic role of the renal kallikrein-kinin system remains unclear. Clearance studies have shown that infusion of kinins into the renal artery produces natriuresis and diuresis (1-4). Micropuncture and tissue-tonicity studies have further suggested that bradykinin-induced redistribution of blood flow toward the medulla and the resulting medullary washout could, at least in part, account for these effects $(5,6)$. On the other hand, recent enzymatic and anatomic data suggest an action of the kallikrein-kinin system within the cortex. In the rabbit and rat kidney, kallikrein and prekallikrein have been localized to the connecting segment $(7,8)$. Although it is clear that kallikrein is a protease which converts low molecular weight kininogen to lysyl-bradykinin (LBK) ${ }^{1}(9)$, it is not known if the latter is generated in the lumen of the connecting segment, in the peritubular blood, or both. Bradykinin has also recently been shown to bind specifically to cortical and medullary collecting tubules of the rabbit (10). In concert, these findings suggest that the kallikrein-kinin system, at least within the cortex, may act to modulate tubule transport directly from the basolateral and/or apical membrane. We therefore studied the effects of LBK on base-line and antidiuretic hormone (ADH)-stimulated osmotic water flow in the rabbit cortical collecting tubule. The data show that LBK from the bath side, but not the lumen, inhibits water flow due to a supramaximal dose of $\mathrm{ADH}$, and that this inhibition is probably mediated via prostaglandin synthesis.

\section{Methods}

General microperfusion methods. In vitro microperfusion of cortical collecting tubules followed the general methods of Burg and Orloff (11). Briefly, normal female New Zealand white rabbits weighing $1.5-2.5 \mathrm{~kg}$

1. Abbreviations used in this paper: ADH, antidiuretic hormone; CVP, calibrated volume pipette; $J_{\mathrm{v}}$, net volume flux; $L_{\mathrm{p}}$, hydraulic conductivity; LBK, lysyl-bradykinin; $V_{\mathrm{i}}$, perfusion rate. 
were killed by decapitation. The left kidney was quickly removed and 1-2-mm coronal slices were cut and placed in chilled, oxygenated Ringersbicarbonate at pH 7.4. Dissection of tubules was done in the same bath as was used for perfusion experiments (below).

Cortical collecting tubules were freehand dissected at $4^{\circ} \mathrm{C}$ using sharpened forceps with the aid of a dissection microscope. The cortical ends of the tubules were cut just distal to their junction with a connecting segment. Tubules were not used if this junction occurred more than one-third of the way into the cortex from the cortical surface. Care was taken not to touch the tubules except at the ends. Tubules were transferred to a thermostatically-controlled chamber of $1 \mathrm{~cm}^{3}$ volume containing ports for constant inflow and removal of bath. The tubules were sucked into holding pipettes containing elastomeric silicone resin (Sylgard 184, Dow Corning Corp., Midland, MI) and cannulated with an inner perfusion pipette. All tubules were perfused in an orthograde direction. Fluid from the tubules was collected under water-equilibrated mineral oil into a calibrated volume pipette (CVP). The volume of the CVP was determined by daily calibration: at the end of the experiment, the perfusion pipette was advanced into a second pipette containing a short $(200 \mu \mathrm{m})$ column of Sylgard backed by mineral oil; perfusate was forced between the Sylgard and oil, and the CVP was filled in triplicate at $37^{\circ} \mathrm{C}$ from this perfusate.

Solutions. Tubules were always bathed in a bath containing (in $\mathrm{mM}$ ): $\mathrm{Na}, 145 ; \mathrm{Cl}, 112 ; \mathrm{HCO}_{3}, 25 ; \mathrm{K}, 5 ; \mathrm{Ca}, 2.4 ; \mathrm{PO}_{4}, 2.3 ; \mathrm{Mg}, 1.0 ; \mathrm{SO}_{4}, 1.0 ;$ acetate, 10; glucose, 8; alanine, 5; and bovine serum albumin, $6 \mathrm{~g} / 100$ ml (CRG-7, Armour Pharmaceutical Co., Tarrytown, NY). The osmolarity of the bath was $295 \mathrm{mOsM} / \mathrm{kg}$. Tubules were initially perfused with a perfusate identical in composition to the bath except without bovine albumin. The tubules were warmed to $37^{\circ} \mathrm{C}$ and allowed to equilibrate for $60-90 \mathrm{~min}$. The perfusate was then changed to one of identical composition except that the $\mathrm{NaCl}$ concentration was $15 \mathrm{mM}$ (osmolarity $=132 \mathrm{mOsM} / \mathrm{kg}$ ), and another $90 \mathrm{~min}$ were allowed. This second perfusate also contained $\left[{ }^{3} \mathrm{H}\right]$ methoxy-inulin (New England $\mathrm{Nu}-$ clear, Boston, MA) exhaustively dialyzed by the method of Schafer et al. (12). Baths were bubbled at $37^{\circ} \mathrm{C}$ with $95 \% \mathrm{O}_{2}: 5 \% \mathrm{CO}_{2}$ to $\mathrm{pH} 7.40$, drawn anaerobically into syringes, and pumped through the perfusion chamber at $\geq 0.6 \mathrm{~cm}^{3} / \mathrm{min}$. Osmolarities of the bath and the $132 \mathrm{mOsM} /$ $\mathrm{kg}$ perfusate containing $\left[{ }^{3} \mathrm{H}\right]$ inulin were measured in duplicate daily.

Calculations. Net volume flux $\left(J_{\mathrm{v}}\right)$ was calculated from: $J_{\mathrm{v}}=V_{\mathrm{i}}$ - $V_{0} / L$, where $V_{\mathrm{i}}=$ perfusion rate in $\mathrm{nl} / \mathrm{min}, V_{0}=$ collection rate in $\mathrm{nl} / \mathrm{min}$, and $L=$ tubule length. $V_{0}$ was measured directly, and $V_{\mathrm{i}}$ was calculated from $V_{\mathrm{i}}=V_{0}\left(\mathrm{cmp}_{0} / \mathrm{cpm}_{\mathrm{i}}\right)$, where $\mathrm{cpm}_{\mathrm{i}}$ and $\mathrm{cpm}_{0}$ are perfusate and collected fluid $\left[{ }^{3} \mathrm{H}\right]$ inulin counts/min per $\mathrm{nl}$, respectively. Samples for $\mathrm{cpm}_{0}$ were counted for $10 \mathrm{~min}$. $L$ was measured directly by eyepiece micrometer. Hydraulic conductivity, $L_{\mathrm{p}}$ (cm/atm per s) was determined from the $J_{\mathrm{v}}$ in response to an imposed osmotic gradient according to DuBois et al. (13): $L_{\mathrm{p}}=\left(1 / \operatorname{RTS}_{\mathrm{b}}{ }^{2}\right)\left\{C_{\mathrm{b}}\left(V_{\mathrm{i}}-V_{0}\right)+C_{\mathrm{i}} V_{\mathrm{i}}\left[\ln \left(C_{\mathrm{b}}-C_{\mathrm{i}}\right) V_{\mathrm{i}}\right.\right.$ $\left.\left.-\ln \left(C_{\mathrm{b}} V_{0}-C_{\mathrm{i}} V_{\mathrm{i}}\right)\right]\right\}$, where $\mathrm{R}$ is the gas constant, $\mathrm{T}$ is temperature $\left({ }^{\circ} \mathrm{K}\right)$, $\mathrm{S}$ is the luminal surface area (assumed lumen diameter, $20 \mu \mathrm{m}$ ), $C_{\mathrm{b}}$ is bath osmolarity (mOsM/kg), $C_{\mathrm{i}}$ is perfusate osmolarity, and $V_{\mathrm{i}}$ and $V_{0}$ have the meanings previously described. It should be noted that the use of the method of DuBois (13) above, without measuring collected fluid osmolarity, rests on two assumptions: (a) that the reflection coefficient of the cortical collecting tubule for $\mathrm{NaCl}=1.0$, and $(b)$ that no net transport of osmotically active substances (ions) occurs. The latter, of course, is untrue at $37^{\circ} \mathrm{C}$. However, the net osmolar efflux rate due to ion transport in this segment is only $\sim 20 \mathrm{pOsM} / \mathrm{mm}$ per $\min (14)$. With a perfusate of $130 \mathrm{mOsM} /$ liter at a perfusion rate of $15 \mathrm{nl} / \mathrm{min}$, the delivered osmolar load is $1950 \mathrm{pOsM} / \mathrm{min}$. Even if bradykinin doubled or halved net ion flux rates, the effect on $L_{\mathrm{p}}$ measured in this way would only be $\sim 1 \%$.
Experimental protocols. Nine experimental protocols were used. The general format of these is as follows: Protocols 1-4: effect of various maneuvers on base-line $L_{\mathrm{p}}$ : (1) Addition of bath arachidonate $(n=5)$, (2) Time control (arachidonate present throughout) $(n=5)$, (3) Effect of bath LBK (arachidonate present throughout) $(n=6),(4)$ Effect of lumen LBK (arachidonate present throughout) $(n=8)$. Protocols 5-9: effect of various preexposures on the subsequent ADH response: (5) Unmodified bath $(n=5)$, (6) Arachidonate preexposure $(n=4)$, (7) Bath LBK plus arachidonate preexposure $(n=7),(8)$ Bath LBK plus indomethacin plus arachidonate preexposure $(n=5)$, (9) Lumen LBK plus arachidonate preexposure $(n=4)$. Specifically, in protocols $1-4$, base-line $L_{\mathrm{p}}$ measurements were made after 180 -min equilibration at $37^{\circ} \mathrm{C}(15)$, then a maneuver was performed, and then $L_{\mathrm{p}}$ was measured again over the next $30 \mathrm{~min}$. In protocol 1, the maneuver performed was the addition of arachidonic acid $(2.5 \mu \mathrm{M})$ to the bath. In protocol 2 , the maneuver was a sham bath change, and thus, this protocol served as a time control. In protocol 3, the maneuver was the addition of LBK $\left(10^{-9} \mathrm{M}\right)$ to the bath, and in protocol 4 , it was LBK addition to the perfusate. In protocols $2-4$, arachidonic acid $(2.5 \mu \mathrm{M})$ was present in the bath from the onset of perfusion.

In contrast, protocols 5-9 examined the effect of various preexposure conditions on the $L_{\mathrm{p}}$ response to ADH $(100 \mu \mathrm{U} / \mathrm{ml})$. In each case, $L_{\mathrm{p}}$ was measured before, and for at least $45 \mathrm{~min}$ following, the addition of ADH $(100 \mu \mathrm{U} / \mathrm{ml})$ to the bath. In protocol 5, the ADH response was assessed in unmodified bath (no arachidonic acid present). In protocol 6 , the ADH response was measured with arachidonic acid $(2.5 \mu \mathrm{M})$ present from the onset of perfusion. In protocol 7 , the bath contained LBK $\left(10^{-9} \mathrm{M}\right)$ for $1 \mathrm{~h}$ before $L_{\mathrm{p}}$ measurements. In protocol 8 , the bath contained indomethacin $(5 \mu \mathrm{M})$ from the start of perfusion, plus LBK $\left(10^{-9} \mathrm{M}\right)$ for $1 \mathrm{~h}$ before $L_{\mathrm{p}}$ measurements. In protocol 9 , the perfusate contained LBK $\left(10^{-9} \mathrm{M}\right)$ for $1 \mathrm{~h}$ before $L_{\mathrm{p}}$ measurements. In protocols $6-9$, arachidonic acid $(2.5 \mu \mathrm{M})$ was present in the bath from the onset of perfusion.

Reagents. Arachidonic acid (99\% purity) and LBK were purchased from Sigma Chemical Co. (St. Louis, MO). The arachidonic acid was kept frozen in the dark under inert gas as a $25 \mathrm{mM}$ stock solution in $0.1 \mathrm{M}$ Tris, $\mathrm{pH} 8$. All bath infusion syringes containing arachidonic acid were kept covered with aluminum foil during the experiment to minimize oxidation. LBK was kept frozen as aliquoted $1 \mu \mathrm{g} / \mu 1$ stock in Ringers plus $2 \%$ bovine albumin and thawed daily as needed. ADH (Arg-Vasopressin, Calbiochem-Behring Corp., San Diego, CA) was kept refrigerated as an aqueous stock solution $(0.5 \mathrm{mg} / \mathrm{ml})$. Indomethacin (Sigma Chemical Co.) was aliquoted and kept frozen as a $1 \mathrm{mg} / \mathrm{ml}$ stock in $75 \mathrm{mM} \mathrm{NaCO}_{3}$.

Statistics. Perfusion rates, $J_{\mathrm{v}}$ and $L_{\mathrm{p}}$, from three to four collections on a given tubule were meaned; then, this value became the value for that tubule for that experimental period. The value " $n$ " equals number of tubules. Since protocols 1-4 studied the effect of a given maneuver on base-line $L_{\mathrm{p}}$ in the same tubule, the two-tailed paired $t$ test was used. In addition, protocols 1,3 , and 4 were compared with protocol 2 (time control) by two-way analysis of variance (16). In protocols 5-9, a control group of tubules was compared with each of several experimental groups, also by two-way analysis of variance. Differences were considered significant if $P<0.05$.

\section{Results}

Base-line $\mathrm{L}_{p}$ : arachidonic acid. Arachidonic acid was present in the bath in experiments using LBK because of concern over the ability of cortical collecting tubules to adequately synthesize 
prostaglandins in a bath containing only Ringers solution. Fetal calf serum was omitted because of likely kininase activity. Schlondorff et al. (17) reported that cortical collecting tubules incubated in Ringers alone have falling rates of prostaglandin synthesis with time and show lack of stimulation of prostaglandin synthesis by ADH, whereas Kirschenbaum et al. (18) reported that cortical collecting tubules incubated in $0.5 \mathrm{mM}$ arachidonic acid do respond to ADH with prostaglandin synthesis. For reasons discussed later, we chose a much lower concentration of arachidonic acid $(2.5 \mu \mathrm{M})$. In this first group of tubules, we examined the response of base-line water permeability to the addition of arachidonic acid. In five tubules, shown in Table I, base-line $L_{\mathrm{p}}$ was measured after $180 \mathrm{~min}$; the bath was then changed to contain $2.5 \mu \mathrm{M}$ arachidonic acid, and $L_{\mathrm{p}}$ was then measured again. The $L_{\mathrm{p}}$ changed by a mean of $-8.7 \pm 4.1$ $\times 10^{-7} \mathrm{~cm} / \mathrm{atm}$ per $\mathrm{s}$. This change was not significant (paired $t$ test). Moreover, the magnitude of the fall in $L_{\mathrm{p}}$ was not different from that seen with time alone (next protocol, by analysis of variance).

Base-line $L_{p}$ : time controls. In five tubules, $L_{\mathrm{p}}$ was measured after 180-min equilibration. The bath then underwent a sham change and $L_{\mathrm{p}}$ was measured again. Arachidonic acid, $2.5 \mu \mathrm{M}$, was present throughout. The results are shown in Table II. Baseline $L_{\mathrm{p}}$ changed by a mean paired difference of $-3.2 \pm 2.2$ $\times 10^{-7} \mathrm{~cm} /$ atm per $\mathrm{s}$; this change was not significant (paired $t$ test).

Base-line $L_{p}$ : bath $L B K$. Six tubules were incubated in 2.5 $\mu \mathrm{M}$ arachidonic acid for the 180 -min equilibration period, after which base-line $L_{\mathrm{p}}$ was measured. Then, the bath was changed to contain arachidonic acid plus LBK $\left(10^{-9} \mathrm{M}\right)$. As shown in Table III, LBK produced a mean change in $L_{\mathrm{p}}$ of $-7.2 \pm 3.6$ $\times 10^{-7} \mathrm{~cm} /$ atm per $\mathrm{s}$. This change was not significant by the paired $t$ test, nor was the magnitude of the fall in $L_{\mathrm{p}}$ significantly different from that seen in the time controls above (analysis of variance).

Base-line $L_{p}$ : lumen $L B K$. In experiments analogous to the previous set, the effect of lumen LBK on base-line $L_{\mathrm{p}}$ was assessed

Table I. Effect of $2.5 \mu \mathrm{M}$ Arachidonic Acid on Base-line Water Pemeability

\begin{tabular}{lccccc} 
& \multicolumn{2}{c}{ Pre-AA } & & \multicolumn{2}{c}{ Post-AA, 2.5 $\mu \mathrm{M}$} \\
\cline { 2 - 5 } Tubule & $V_{\mathrm{i}}$ & \multicolumn{1}{c}{$L_{\mathrm{p}}$} & \multicolumn{2}{c}{$V_{\mathrm{i}}$} & \multicolumn{1}{c}{$L_{\mathrm{p}}$} \\
\hline 1 & 18.6 & 7.7 & 19.7 & -0.5 \\
2 & 19.0 & 18.0 & 16.9 & 11.1 \\
3 & 15.7 & 14.7 & 20.9 & 12.0 \\
4 & 16.5 & 28.3 & 17.1 & 27.2 \\
5 & 14.0 & 48.7 & 13.2 & 24.3 \\
Mean & 16.8 & 23.5 & $17.6^{*}$ & $14.8^{*}$ \\
SE & 0.9 & 7.1 & 1.3 & 4.9 \\
& & & & \\
\hline
\end{tabular}

AA, arachidonic acid.

*, NS compared with previous period (paired $t$ test).
Table II. Base-line Water Permeability Time Controls with Arachidonic Acid

\begin{tabular}{lccccc}
\hline & \multicolumn{2}{c}{ Period 1 } & & \multicolumn{2}{c}{ Period 2 } \\
\cline { 2 - 5 } Tubule & $V_{\mathrm{i}}$ & $L_{\mathrm{p}}$ & $V_{\mathrm{i}}$ & $L_{\mathrm{p}}$ \\
\hline 1 & 12.9 & 36.5 & 16.9 & 25.0 \\
2 & 14.7 & 32.4 & 16.6 & 28.7 \\
3 & 14.4 & 21.3 & 14.7 & 22.0 \\
4 & 13.8 & 20.5 & 17.1 & 20.0 \\
5 & 15.5 & 15.3 & 12.4 & 14.3 \\
Mean & 14.3 & 25.2 & $15.1^{*}$ & $22.0^{*}$ \\
SE & 0.4 & 3.9 & 0.9 & 2.4 \\
\hline
\end{tabular}

*, NS.

in eight tubules. The mean change in $L_{p}$ was $-0.7 \pm 2.0 \times 10^{-7}$ $\mathrm{cm} / \mathrm{atm}$ per s, as shown in Table IV. Again, this change was not significant by paired analysis, and was not different from that seen in the time controls above (analysis of variance).

$A D H$ response: no arachidonic acid. Five control tubules were incubated during the 180 -min equilibration period without arachidonic acid. Then, the response to a supramaximal dose of ADH $(100 \mu \mathrm{U} / \mathrm{ml})$ was measured for $45 \mathrm{~min}$. The $L_{\mathrm{p}}$ in the 25-35-min period post-ADH are shown in Table V. $L_{\mathrm{p}}$ for the 15-25 and 35-45-min periods were $132.6 \pm 11.6 \times 10^{-7}$ and $115.4 \pm 10.9 \times 10^{-7} \mathrm{~cm} /$ atm per $\mathrm{s}$, respectively.

$A D H$ response: arachidonic acid present. Four additional control tubules were incubated during the 180 -min equilibration period in $2.5 \mu \mathrm{M}$ arachidonic acid and their subsequent response to a supramaximal dose of ADH was assessed. These tubules are also shown in Table V. Mean $L_{\mathrm{p}}$ 's for the $15-25$ and 3545-min post-ADH periods were $121.3 \pm 13.3 \times 10^{-7}$ and $130.6 \pm 17.1 \times 10^{-7} \mathrm{~cm} /$ atm per $\mathrm{s}$. The two groups shown in Table $\mathrm{V}$ were not significantly different at any time period fol-
Table III. Effects of $10^{-9} \mathrm{M}$ Bath $\mathrm{LBK}$ on Base-line Water Permeability

\begin{tabular}{lrrrr} 
& \multicolumn{2}{l}{ Prebath LBK } & & \multicolumn{2}{l}{ Postbath LBK } \\
\cline { 2 - 5 } Tubule & \multicolumn{1}{c}{$V_{\mathrm{i}}$} & $L_{\mathrm{p}}$ & \multicolumn{1}{c}{$V_{\mathrm{i}}$} & \multicolumn{1}{c}{$L_{\mathrm{p}}$} \\
\hline 1 & 17.9 & 52.8 & 16.8 & 31.1 \\
2 & 17.1 & 27.2 & 19.5 & 18.2 \\
3 & 17.8 & 24.8 & 14.6 & 18.5 \\
4 & 15.3 & 1.1 & 16.0 & 0.5 \\
5 & 13.0 & 19.0 & 15.8 & 9.0 \\
6 & 14.7 & 6.3 & 13.9 & 10.6 \\
Mean & 15.9 & 21.9 & $16.1^{*}$ & $14.7^{*}$ \\
SE & 0.8 & 7.5 & 0.8 & 4.3 \\
\hline
\end{tabular}

*, NS. 
Table IV. Effect of $10^{-9} \mathrm{M}$ Lumen $L B K$ on Base-line Water Permeability

\begin{tabular}{llrrrr}
\hline & \multicolumn{2}{l}{ Prelumen LBK } & & \multicolumn{2}{c}{ Postlumen LBK } \\
\cline { 2 - 3 } \cline { 5 - 6 } Tubule & $V_{\mathrm{i}}$ & \multicolumn{1}{c}{$L_{\mathrm{p}}$} & & $V_{\mathrm{i}}$ & \multicolumn{1}{c}{$L_{\mathrm{p}}$} \\
\hline 1 & 13.3 & 18.7 & & 11.7 & 16.0 \\
2 & 11.3 & 9.8 & & 8.6 & 10.5 \\
3 & 10.9 & 24.0 & & 8.8 & 12.0 \\
4 & 11.3 & 9.8 & & 8.6 & 11.8 \\
5 & 13.3 & 15.3 & & 13.4 & 10.3 \\
6 & 15.5 & 20.3 & & 12.4 & 23.0 \\
7 & 14.0 & 9.0 & & 12.4 & 12.8 \\
8 & 16.5 & 11.8 & & 15.5 & 16.8 \\
Mean & 13.3 & 14.8 & & 11.4 & 14.2 \\
SE & 0.7 & 2.0 & 0.9 & 1.5
\end{tabular}

*, NS.

lowing ADH (by unpaired analysis). Therefore, for comparisons to subsequent experimental groups, all tubules in Table $\mathrm{V}$ were combined as a single control group with mean values as shown

Table V. Control Response to $\mathrm{ADH}(100 \mu \mathrm{U} / \mathrm{ml})$ without and with Preincubation in $2.5 \mu M$ Arachidonic Acid

\begin{tabular}{|c|c|c|c|}
\hline \multirow[b]{2}{*}{ Tubule } & \multirow[b]{2}{*}{$L$} & \multirow[b]{2}{*}{$V_{\mathbf{i}}$} & \multirow{2}{*}{$\begin{array}{l}25-35 \mathrm{~min} \\
\text { Post-ADH } \\
L_{\mathrm{D}}\end{array}$} \\
\hline & & & \\
\hline & $m m$ & & \\
\hline \multicolumn{4}{|l|}{ No arachidonic acid } \\
\hline 1 & 1.90 & 11.8 & 85.0 \\
\hline 2 & 2.10 & 10.1 & 130.0 \\
\hline 3 & 2.30 & 11.3 & 149.0 \\
\hline 4 & 1.60 & 17.0 & 144.5 \\
\hline 5 & 1.50 & 16.3 & 128.5 \\
\hline Mean & & 13.3 & 127.4 \\
\hline $\mathrm{SE}$ & & 1.4 & 11.3 \\
\hline \multicolumn{4}{|c|}{ With arachidonic acid } \\
\hline 1 & 1.90 & 11.6 & 94.0 \\
\hline 2 & 1.40 & 17.9 & 141.0 \\
\hline 3 & 1.20 & 18.2 & 122.5 \\
\hline 4 & 2.50 & 20.3 & 173.0 \\
\hline Mean & & 17.0 & 132.6 \\
\hline SE & & 1.91 & 6.6 \\
\hline$P^{*}$ & & NS & NS \\
\hline Combined means & & 14.9 & 129.7 \\
\hline SE & & 1.3 & 9.1 \\
\hline
\end{tabular}

L, length.

*, compared with group without arachidonic acid (unpaired $t$ test).

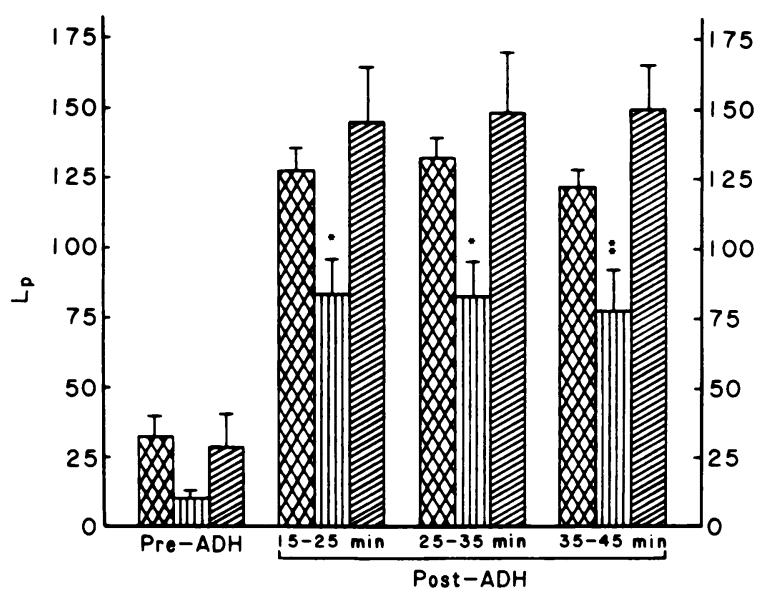

Figure 1. Base-line hydraulic conductivity (cm/atm per $\mathrm{s} \times 10^{7}$, left) and response to $\mathrm{ADH}(100 \mu \mathrm{U} / \mathrm{ml}$, right $)$ at $15-25,25-35$, and $35-$ $45 \mathrm{~min}$. The control group (cross-hatched bars) is the combined control group from Table V. A second group was exposed to bath LBK $\left(10^{-9} \mathrm{M}\right)$ for $1 \mathrm{~h}$ before ADH was added (vertical-line bars). A third group was exposed to bath LBK and indomethacin $(5 \mu \mathrm{M})$ for $1 \mathrm{~h}$ before ADH (diagonal-line bars). ${ }^{*}, P<0.02$; ${ }^{* *}=P<0.01$ compared with control group, bath LBK plus indomethacin group, and lumen LBK group (Table VIII) by analysis of variance.

at the bottom of Table V. As shown in Fig. 1, the base-line $L_{\mathrm{p}}$ and three post-ADH period $L_{\mathrm{p}}$ 's for this combined control group were $32.5 \pm 8.3 \times 10^{-7}, 127.6 \pm 8.4 \times 10^{-7}, 129.7 \pm 9.1 \times 10^{-7}$, and $122.2 \pm 9.4 \times 10^{-7} \mathrm{~cm} /$ atm per s, respectively. Subsequent protocols had $2.5 \mu \mathrm{M}$ arachidonic acid in the bath throughout.

$A D H$ response: pre-incubation with bath $L B K$. Seven tubules were exposed for $1 \mathrm{~h}$ to $10^{-9} \mathrm{M}$ bath LBK before ADH administration. As shown in Table VI and Fig. 1, this exposure resulted in a markedly blunted subsequent $\mathrm{ADH}$ response: the three periods following ADH had mean $L_{\mathrm{p}}$ of $83.4 \pm 13.3 \times 10^{-7}$, $82.7 \pm 13.1 \times 10^{-7}$, and $77.4 \pm 15.1 \times 10^{-7} \mathrm{~cm} / \mathrm{atm}$ per $\mathrm{s}$, respectively. These differences were significantly different from the control group ADH response (see Fig. 1 for $P$ values). The base-line $L_{\mathrm{p}}$ after 1-h incubation with $10^{-9}$ bath LBK was not different from the control period base-line $L_{\mathrm{p}}\left(10.6 \pm 2.2 \times 10^{-7}\right.$ vs. $32.5 \pm 8.3 \times 10^{-7}$, NS by analysis of variance).

Table VI gives the perfusion rates for the $25-35$-min postADH period. These were not significantly different from the perfusion rates for the comparable control period. Likewise, perfusion rates for the 35-45-min period were not different. However, for the 15-25-min post-ADH period, perfusion rates for the bath LBK group were significantly higher than control $(17.9 \pm .8$ vs. $15.1 \pm .9 \mathrm{nl} / \mathrm{min}, P<0.03)$. At these rapid perfusion rates, however, the collected fluid is far from being in osmotic equilibration with the bath. Moreover, if any error was introduced, it would have been in the direction of lessening the difference between the control and LBK $L_{\mathrm{p}}$ 's (13).

$A D H$ response: bath $L B K$ plus indomethacin. Since available evidence implicates prostaglandins as mediators of bradykinin actions in several tissues, experiments using the cyclooxygenase 
Table VI. Response to $\mathrm{ADH}(100 \mu \mathrm{U} / \mathrm{ml})$ after Preexposure to $10^{-9} \mathrm{M}$ Bath LBK

\begin{tabular}{lccc} 
& & & $\begin{array}{c}25-35 \mathrm{~min} \\
\text { Post-ADH }\end{array}$ \\
\hline Tubule & $L$ & $V_{\mathrm{i}}$ & $L_{\mathrm{p}}$ \\
\hline 1 & 2.60 & 17.7 & 66.0 \\
2 & 1.80 & 18.7 & 55.5 \\
3 & 1.75 & 17.8 & 75.0 \\
4 & 1.70 & 19.5 & 114.0 \\
5 & 1.45 & 17.6 & 141.5 \\
6 & 1.80 & 18.3 & 41.0 \\
7 & 1.50 & 15.4 & 86.0 \\
Means & & 17.9 & 82.7 \\
SE & & 0.5 & 13.1 \\
$P^{*}$ & & NS & $<0.02$ \\
& & &
\end{tabular}

* Compared with combined control group (Table V), bath LBK group plus indomethacin (Table VII), and lumen LBK group (Table VIII) by analysis of variance.

inhibitor indomethacin during bath LBK exposure were performed. Preliminary attempts at using $5 \times 10^{-5} \mathrm{M}$ indomethacin resulted in tubule deterioration. Tubules remained viable, however, in $5 \times 10^{-6} \mathrm{M}$ indomethacin. In five tubules exposed to indomethacin from the onset of perfusion plus $10^{-9} \mathrm{M}$ bath LBK for $1 \mathrm{~h}$ before ADH, the base-line and post-ADH $L_{\mathrm{p}}$, as shown in Table VII and Fig. 1, were $28.6 \pm 7.6 \times 10^{-7}, 144.8 \pm 20.5$ $\times 10^{-7}, 148.1 \pm 22.5 \times 10^{-7}$, and $148.4 \pm 23.2 \times 10^{-7} \mathrm{~cm} / \mathrm{atm}$ per s, respectively. The base-line $L_{\mathrm{p}}$ was not statistically different from either the control or bath LBK base-line $L_{p}$ (analysis of variance). The post-ADH $L_{\mathrm{p}}$, however, were significantly different from the bath LBK values, but not different from control.

Table VII. Response to ADH $(100 \mu \mathrm{U} / \mathrm{ml})$ after Preexposure to $10^{-9} M$ Bath LBK Plus Indomethacin (5 $\left.\mu \mathrm{M}\right)$

\begin{tabular}{llcc} 
& & & $\begin{array}{c}25-35 \mathrm{~min} \\
\text { Post-ADH }\end{array}$ \\
& $L$ & $V_{\mathrm{i}}$ & $L_{\mathrm{p}}$ \\
\hline 1 & 1.84 & 13.2 & 150.5 \\
2 & 1.25 & 18.0 & 187.0 \\
3 & 1.90 & 19.9 & 85.0 \\
4 & 1.50 & 17.0 & 112.0 \\
5 & 2.10 & 18.7 & 206.0 \\
Means & & 17.4 & 148.1 \\
SE & & 1.1 & 22.5 \\
$P^{*}$ & & $\mathrm{NS}$ & $\mathrm{NS}$ \\
& & &
\end{tabular}

* Compared with combined group (Table V) and lumen LBK group (Table VIII) by analysis of variance.
Thus, indomethacin reversed to normal the inhibition of ADH action seen with bath LBK alone.

The perfusion rates for the three post-ADH periods in this group $(18.5 \pm 1.0,17.4 \pm 1.1$, and $17.9 \pm 0.7 \mathrm{nl} / \mathrm{min}$, respectively) were not significantly different from those for the comparable bath LBK periods.

$A D H$ response: lumen $L B K$. Because kallikrein and low molecular weight kininogen both can be found in the urine (9), it is possible that generation of LBK occurs within the lumen of the connecting segment and subsequently acts upon the cortical collecting tubule from the luminal surface. We, therefore, examined the effect of $10^{-9} \mathrm{M}$ lumen LBK on the subsequent $\mathrm{ADH}$ response. The responses at 25-35-min post-ADH are shown in Table VIII, and are representative of the $L_{\mathrm{p}}$ values observed at $15-25$ and $35-45 \mathrm{~min}$. There was no significant difference between the ADH response in this group of tubules and that of the control or bath LBK plus indomethacin groups. The ADH response was, however, significantly higher than that for the bath LBK group (analysis of variance).

\section{Discussion}

These studies are important because they demonstrate, for the first time, a direct epithelial effect of bradykinin on nephron transport in vitro. Four aspects of the present studies deserve elaboration: $(a)$ correlation with bradykinin effects in $\mathrm{ADH}$ responsive anuran urinary bladders; $(b)$ the role of prostaglandins in bradykinin's action; $(c)$ the results with luminal LBK; and (d) the significance of these studies with respect to understanding the function of the renal kallikrein-kinin system.

The interactions of bradykinin and $\mathrm{ADH}$-mediated water flow in the toad bladder have been previously addressed in two ways. First, exogenous bradykinin and LBK have been added to the mucosal and serosal surfaces. Furtado (19) found no effect of either of these kinins on basal water flow, but ADH action

Table VIII. Response to $A D H(100 \mu U / m l)$ after Preexposure to $10^{-9} \mathrm{M}$ Lumen $\mathrm{LBK}$

\begin{tabular}{llcc}
\hline & & & $\begin{array}{c}25-35 \mathrm{~min} \\
\text { Post-ADH }\end{array}$ \\
\hline Tubule & $L$ & $V_{\mathrm{i}}$ & $L_{\mathrm{p}}$ \\
\hline 1 & 1.90 & 17.7 & 151.8 \\
2 & 1.95 & 19.6 & 186.1 \\
3 & 0.90 & 14.3 & 125.6 \\
4 & 2.80 & 27.8 & 155.0 \\
Mean & & 19.9 & 154.6 \\
SE & & & 12.4 \\
$P^{*}$ & & & $\mathrm{NS}$ \\
& & &
\end{tabular}

* Compared with control group, and bath LBK group plus indomethacin (by analysis of variance). 
was inhibited by both kinins. Second, since the toad bladder contains all components of the kallikrein-kinin cascade, another approach has been to inhibit kallikrein protease activity with aprotinin. Depending upon the species of toad, this maneuver has been reported to either have no effect $(20)$ or to stimulate $\mathrm{ADH}$-mediated water flow (21). Likewise, enhancement of endogenous kinin levels in the toad bladder by kininase inhibitors has led to inhibition of the osmotic response to ADH (21). In both the studies of Orce et al. (20) and Carvounis et al. (21), manipulation of the toad bladder endogenous kallikrein-kinin system produced no effect on non-ADH-stimulated (base-line) water flow. In concert, this evidence from the toad bladder has suggested that kinins inhibit ADH-mediated water flow, but do not alter basal water permeability. The present studies using isolated, perfused collecting tubules agree, at least qualitatively, with these previous toad bladder data.

In our studies, the inhibition of $\mathrm{ADH}$ action by preexposure to bath LBK was completely reversed by indomethacin, suggesting a role for prostaglandins in this bradykinin effect. Bradykinin has been reported to stimulate prostaglandin $E_{2}$ synthesis in cultured dog cortical collecting duct cells (22) and in MDCK cells (which have some properties in common with collecting ducts) (23) at the concentration $\left(10^{-9} \mathrm{M}\right)$ used here. Also, it has been known since the studies of Grantham and Orloff (24) in the cortical collecting tubule and Orloff et al. (25) in the toad bladder that prostaglandin $\mathrm{E}_{1}$ can inhibit the hydroosmotic response to ADH, at least in part (26) by inhibiting the generation of cyclic AMP. Our experiments are therefore consistent with a model in which bradykinin stimulates endogenous prostaglandin synthesis in cortical collecting tubules, such that the subsequent hydroosmotic action of $\mathrm{ADH}$ is, in turn, inhibited by these prostaglandins.

Two important points should be made concerning this interpretation, however. First, it is possible that part of the increase in $L_{\mathrm{p}}$ seen in the indomethacin-treated tubules was due to phosphodiesterase inhibition. Flores and Sharp (27) reported about $15-20 \%$ inhibition of phosphodiesterase activity in the toad urinary bladder by indomethacin at the concentration $(5 \mu \mathrm{M})$ used here. It is unclear, however, whether this action of the drug produces a quantitatively significant effect on water flow. Indomethacin alone does not alter basal water flow in the toad bladder $(28,29)$. Moreover, even when toad bladder phosphodiesterase activity is inhibited virtually $100 \%$ by theophylline (27), the resulting water flow is still only a fraction of that seen at low doses of ADH (30). Indomethacin does not alter rat renal medullary phosphodiesterase activity $(31,32)$, and in contrast to its effects in the toad bladder, in the case of isolated, perfused cortical collecting tubules bathed in arachidonic acid, indomethacin does not augment $L_{\mathrm{p}}$ in response to submaximal ADH (18). As far as we are aware, the effect of indomethacin on phosphodiesterase activity in rabbit cortical collecting tubules has not been directly determined. On the whole, however, we feel that the most likely mechanism for indomethacin-induced reversal of the bradykinin effect reported here is inhibition of prostaglandin synthesis.
The second point concerning the apparent prostaglandin mediation of bradykinin's effect concerns the temporal sequence of these experiments. Our data show that preexposure of tubules to bradykinin blunts the subsequent ADH response. It is not clear that bradykinin added after ADH would have had an identical effect. We performed these experiments at $37^{\circ} \mathrm{C}$ because, based on the data of Hall and Grantham (15), we were unsure whether or not cortical collecting tubules can synthesize prostaglandins normally at room temperature. If, at $37^{\circ} \mathrm{C}$, the decline in $L_{\mathrm{p}}$ which begins about $45 \mathrm{~min}$ post-ADH (15) is due to prostaglandin synthesis, then the blunted $L_{\mathrm{p}}$ seen at 30 -min post-ADH in our bradykinin-exposed tubules may have represented an experimental condition in which ADH-mediated prostaglandin synthesis had not yet peaked. The sequential exposure to the two peptides which we employed may not necessarily occur in vivo; rather, the epithelium might be exposed to bradykinin during maximal ADH-induced prostaglandin synthesis. If this were the case, a further reduction in $L_{p}$ by bradykinin might depend on whether or not bradykinin and $\mathrm{ADH}$ stimulate the same prostaglandin end products and/or share a common intracellular pool of arachidonic acid. We have not addressed this reverse sequence of peptide exposure because of the difficulties inherent in interpreting falling $L_{\mathrm{p}}$ at $37^{\circ} \mathrm{C}$.

We used arachidonic acid in the bathing medium to ensure optimal conditions for hormone-mediated prostaglandin synthesis. Moreover, we sought a concentration of arachidonic acid which would minimize nonspecific augmentation of prostaglandin synthesis but still allow hormone-mediated stimulation to occur. In this regard, Schwartzman et al. (33) found, in the isolated perfused rabbit kidney, that $6.6 \mu \mathrm{M}$ arachidonic acid produced only a $50 \%$ increase in prostaglandin synthesis, whereas bradykinin produced a nearly $1,200 \%$ increase. Similarly, in the colon, even an arachidonic acid concentration of $0.5 \mathrm{mM}(200$ fold the present dose) failed to quantitatively mimic the action of bradykinin on chloride transport (34). Kirschenbaum et al. (18) found that $50 \mu \mathrm{M}$ arachidonic acid in the bath inhibited the hydroosmotic response of in vitro cortical collecting tubules to $2.5 \mu \mathrm{U} / \mathrm{ml} \mathrm{ADH}$. In contrast, Stokes (35) found that neither 10 nor $5 \mu \mathrm{M}$ arachidonic acid altered base-line water permeability or the response to $1 \mu \mathrm{U} / \mathrm{ml} \mathrm{ADH}$. These differences underscore the dose-dependent effect of exogenously added arachidonic acid on apparent endogenous prostaglandin synthesis rates. Our own data suggest that $2.5 \mu \mathrm{M}$ arachidonic acid did not stimulate nonspecific prostaglandin production to an extent which would inhibit maximal ADH action, since the osmotic permeabilities with and without this dose of arachidonic acid were virtually identical (Table V). Base-line water permeabilities were also not altered by this dose of arachidonic acid.

It should be noted that, even though intrarenal infusions of bradykinin produce renal prostaglandin release $(33,36)$, several clearance studies have been unable to implicate prostaglandins in the whole-kidney diuretic response to bradykinin $(4,37,38)$. As discussed in the introduction, however, such peptide infusions produce multiple intrarenal effects. It is possible that medullary washout persists in the face of cyclooxygenase inhibitors to an 
extent such that the normalized collecting duct water permeability cannot be expressed in the final urine osmolarity.

Our results with luminal addition of LBK were negative. These studies are thus at variance with those of Furtado (19) who found equivalent inhibition of $\mathrm{ADH}$ action in the toad bladder by bradykinin added to either the mucosal or serosal side. In addition, in a preliminary report, Garcia-Perez and Smith (39) have suggested that bradykinin stimulates prostaglandin release from cultured canine collecting tubule cells when applied to the apical side of the cell monolayer, but not the basolateral side. It is not clear why basolateral bradykinin would produce no prostaglandin synthesis in cultured cells, but would inhibit ADH action via an indomethacin-sensitive mechanism in intact perfused tubules. Species differences may play a role. It is also possible that intact tubules and cultured cells behave differently with respect to prostaglandin synthesis. For example, $33 \mu \mathrm{M}$ arachidonic acid produces sevenfold stimulation of prostaglandin synthesis in intact rabbit cortical collecting tubules, but 250 -fold stimulation in cultured collecting duct cells from the same species (40). The reason(s) for this quantitative difference are not clear. Our studies with luminal LBK may be at variance with the toad bladder studies of Furtado (19) because of differences in the dose of LBK used. It is possible that the high dose $\left(10^{-6} \mathrm{M}\right)$ of LBK employed by Furtado would also act from the lumen in collecting tubules. We have not examined this issue. However, we chose the LBK dose of $10^{-9} \mathrm{M}$ because this concentration stimulates prostaglandin synthesis at just above the half-maximal rate in cultured collecting duct cells (22), and it is quite close to the normal human urine LBK concentration (41). The apparent sidedness (basolateral) for bradykinin's action demonstrated here appears inconsistent with immunohistochemical studies showing an apical location of distal nephron kallikrein (42). It should be noted, however, that in the isolated perfused kidney, more kallikrein-like activity is spontaneously released into the venous effluent than into the urine per unit time (43). Moreover, Yamada and Erdos (44) have recently reported isolation of a basolateral kallikrein from rat kidney with properties which are different from urinary kallikrein. Taken together, these studies and our data suggest that an action of bradykinin from the basolateral side in vivo is possible. Our negative luminal studies do not rule out the potential for bradykinin action from this membrane under certain conditions, however.

Finally, the present results help to further define the physiologic role of the renal kallikrein-kinin system. Water loading increases kallikrein excretion $(9,45)$, suggesting activation of the kallikrein-kinin system. In addition, examination of circadian rhythms of urine volume and urinary kallikrein excretion during spontaneous drinking shows that these vary linearly with each other (46). These studies thus suggest that kinin activation occurs during water diuresis when ADH levels are either declining or are suppressed. In this context, we have interpreted our data as showing no effect of kinins on osmotic water permeability in the absence of $\mathrm{ADH}$; thus, it makes a regulatory role for bradykinin in the absence of ADH unlikely. However, we cannot absolutely rule out an LBK effect on base-line $L_{\mathrm{p}}$. In percentage terms, bath LBK addition over $30 \mathrm{~min}$ appeared to decrease base-line $L_{\mathrm{p}}$ more $(33 \%)$ than either lumen addition $(5 \%)$ or time controls $(13 \%)$, but this decrease was not statistically different from that seen in the time controls. After exposure to bath LBK for $1 \mathrm{~h}$, the pre-ADH $L_{\mathrm{p}}$ (a "base-line" $L_{\mathrm{p}}$ term) was not significantly lower than similar measurements in control, lumen LBK, or bath LBK plus indomethacin groups, all of which were compared by analysis of variance $(P=0.053)$. However, analysis of variance is weighted toward avoiding an "alpha" error, i.e. concluding that two groups are different when they are not. Particularly with the relatively small sample size we employed, analysis of variance may commit a beta type II error; that is, it may conclude that no difference exists between two groups when such a difference does exist (16). Therefore, it is possible that exposure to bath LBK for $1 \mathrm{~h}$ does indeed lower base-line $L_{\mathrm{p}}$. Studies utilizing a large number of tubules would probably be needed in order to demonstrate such a difference.

On the other hand, administration of ADH to dogs and rats results in enhanced urinary kallikrein excretion $(47,48)$ and since infusions of bradykinin antagonize the action of ADH in clearance experiments (1), these studies have suggested that the kallikrein-kinin system may serve as a feedback inhibitor of ADH action. Although the examination of kallikrein excretion rates suffers the drawback that these determinations may not reflect rates of intraluminal or peritubular generation of LBK, urinary kinins have been correlated with diuresis in at least one study (49). Thus, this second group of studies suggests activation of the kallikrein-kinin system when ADH levels are high. If our data represent a physiologic event, then the inhibition of $\mathrm{ADH}$ action by LBK would be consistent with activation of the kallikrein-kinin system at high ADH levels.

\section{Acknowledgments}

The authors thank Ms. Susan Corona and Ms. Amy Womack for expert technical assistance, Ms. Syd Harned and Ms. Betty Shearer for typing the manuscript, and Dr. William Campbell for helpful discussions.

This work was supported by National Institutes of Health Research grants 5-R01-AM-23901 and 5-R01-AM-14677, and National Institutes of Health Training grant 5-T32-AM-07257. Dr. Jacobson is the recipient of National Institutes of Health Research Career Development Award 1-K04-AM-00537.

\section{References}

1. Barraclough, M. A., and I. H. Mills. 1965. Effect of bradykinin on renal function. Clin. Sci. 28:69-74.

2. Webster, M. E., and S. P. Gilmore. 1964. Influence of kallidin10 on renal function. Am. J. Physiol. 206:714-718.

3. Willis, L. R., J. H. Ludens, J. B. Hook, and H. E. Williamson. 1969. Mechanism of natriuretic action of bradykinin. Am. J. Physiol. 217:1-5.

4. Blasingham, M. C., and A. Nasjletti. 1979. Contribution of renal prostaglandins to the natriuretic action of bradykinin in the dog. Am. J. Physiol. 237:F182-F187. 
5. Fadem, S. Z., G. Hernandez-Llamas, R. V. Patak, S. G. Rosenblatt, M. D. Lifschitz, and J. H. Stein. 1982. Studies on the mechanism of sodium excretion during drug-induced vasodilatation in the dog. J. Clin. Invest. 69:604-610.

6. Willis, L. R. 1977. Effect of bradykinin on the renal medullary osmotic gradient in water diuresis. Eur. J. Pharmacol. 45:173-183.

7. Omata, K., O. A. Carretero, A. G. Scicli, and B. A. Jackson. 1982. Localization of active and inactive kallikrein (kininogenase activity) in the microdissected rabbit kidney. Kidney Int. 22:602-607.

8. Proud, D., M. A. Knepper, and J. J. Pisano. 1983. Distribution of immunoreactive kallikrein along the rat nephron. Am. J. Physiol. 244:F510-F515.

9. Carretero, O. A., and A. G. Scicli. 1980. The renal kallikreinkinin system. Am. J. Physiol. 238:F247-F255.

10. Tomita, K., and J. J. Pisano. 1983. Binding of $\left[{ }^{3} \mathrm{H}\right]$ bradykinin in isolated nephron segments of the rabbit. Fed. Proc. 42:1021. (Abstr.)

11. Burg, M. B., and J. Orloff. 1968. Control of fluid absorption in the renal proximal tubule. J. Clin. Invest. 47:2016-2024.

12. Schafer, J. A., S. L. Troutman, and T. E. Andreoli. 1974. Volume reabsorption, transepithelial potential difference, and ionic permeability properties in mammalian superficial proximal straight tubules. J. Gen. Physiol. 64:582-607.

13. DuBois, R. A., A. Verniory, and M. Abramow. 1976. Computation of the osmotic water permeability of perfused tubule segments. Kidney Int. 10:478-479.

14. Stokes, J. B. 1983. Ion transport by cortical and outer medullary collecting tubule. Kidney Int. 22:473-484.

15. Hall, D. A., and J. J. Grantham. 1980. Temperature effect of ADH response of isolated perfused rabbit collecting tubules. Am. J. Physiol. 239:F595-F601.

16. Snedecor, G. W., and W. G. Cochran. 1967. Statistical Methods. Iowa State University Press, Ames, IA. Sixth ed. 593 pp.

17. Schlondorff, D., J. A. Satriano, and G. J. Schwartz. 1983. Effect of antidiuretic hormone on prostaglandin $\mathrm{E}_{2}$ synthesis by isolated cortical and medullary collecting tubules. Adv. Prostaglandin Thromboxane Leukotriene Res. 11:525-527.

18. Kirschenbaum, M. A., A. G. Lowe, W. Trizna, and L. G. Fine. 1982. Regulation of vasopressin action by prostaglandins. Evidence for prostaglandin synthesis in the rabbit cortical collecting tubule. J. Clin. Invest. 70:1193-1204.

19. Furtado, M. R. F. 1971. Inhibition of the permeability response to vasopressin and oxytocin in the toad bladder. J. Membr. Biol. 4:165178.

20. Orce, G. C., G. A. Castillo, and H. S. Margolius. 1980. Inhibition of short-circuit current in toad urinary bladder by inhibitors of glandular kallikrein. Am. J. Physiol. 239:F459-F465.

21. Carvounis, C. P., G. Carvounis, and L. A. Arbeit. 1981. Role of the endogenous kallikrein-kinin system in modulating vasopressinstimulated water flow and urea permeability in the toad bladder. J. Clin. Invest. 67:1792-1796.

22. Garcia-Perez, A., and W. L. Smith. 1983. Use of monoclonal antibodies to isolate cortical collecting tubule cells: AVP induces PGE release. Am. J. Physiol. 244:C211-C220.

23. Hassid, A. 1981. Transport-active renal tubular epithelial cells (MDCK and LLC-PK $_{1}$ in culture. Prostaglandin biosynthesis and its regulation by peptide hormones and ionophore. Prostaglandins. 21:9851001.

24. Grantham, J. J., and J. Orloff. 1968. Effect of prostaglandin $E_{1}$ on the permeability response of the isolated collecting tubule to vaso- pressin, adenosine $3^{\prime}, 5^{\prime}$-monophosphate, and theophylline. J. Clin. Invest. 47:1154-1161.

25. Orloff, J., J. S. Handler, and S. Bergstrom. 1965. Effect of prostaglandin $\mathrm{PGE}_{1}$ on the permeability response of toad bladder to vasopressin, theophylline, and adenosine $3^{\prime}, 5^{\prime}$-monophosphate. Nature (Lond.). 205:397-398.

26. Schlondorff, D., C. P. Carvounis, M. Jacoby, J. A. Satriano, and S. D. Levine. 1981. Multiple sites for interaction of prostaglandin and vasopressin in toad urinary bladder. Am. J. Physiol. 241:F625-F631.

27. Flores, A. G. A., and G. W. G. Sharp. 1972. Endogenous prostaglandins and osmotic water flow in the toad bladder. Am. J. Physiol. 233:1392-1397.

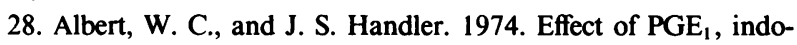
methaçin, and polyphloretin phosphate on toad bladder response to ADH. Am. J. Physiol. 226:1382-1386.

29. Zusman, R. M., H. R. Keiser, and J. S. Handler. 1977. Vasopressin-stimulated prostaglandin $\mathrm{E}$ biosynthesis in the toad urinary bladder. Effect on water flow. J. Clin. Invest. 60:1339-1347.

30. Flores, J., P. A. Witkum, B. Beckman, and G. W. G. Sharp. 1975. Stimulation of osmotic water flow in toad bladder by prostaglandin $\mathrm{E}_{1}$. Evidence for different compartments of cyclic AMP. J. Clin. Invest. 56:256-262.

31. Lum, G. M., G. A. Aisenbrey, M. J. Dunn, T. Berl, R. W. Schrier, and K. M. McDonald. 1977. In vivo effect of indomethacin to potentiate the renal medullary cyclic AMP response to vasopressin. $J$. Clin. Invest. 59:8-13.

32. Berl, T., A. Raz, H. Wald, J. Horowitz, and W. Czaczkes. 1977. Prostaglandin synthesis inhibition and the action of vasopressin: studies in man and rat. Am. J. Physiol. 232:F529-F537.

33. Schwartzman, M., F. Liberman, and A. Raz. 1981. Bradykinin and angiotensin II activation of arachidonic acid deacylation and prostaglandin $\mathrm{E}_{2}$ formation in rabbit kidney. J. Biol. Chem. 256:2329-2333.

34. Munsch, M. W., J. F. Kachur, R. J. Miller, M. Field, and J. S. Stoff. 1983. Bradykinin-stimulated electrolyte secretion in rabbit and guinea pig intestine. J. Clin. Invest. 71:1073-1087.

35. Stokes, J. B. 1979. Effects of endogenous and exogenous prostaglandins on $\mathrm{ADH}$-dependent osmotic water permeability $\left(\mathrm{P}_{\mathrm{f}}\right)$ and $\mathrm{Na}$ efflux coefficient $\left(\mathrm{K}_{\mathrm{Na}}\right)$ across the isolated cortical collecting tubule. Kidney Int. 16:839. (Abstr.)

36. McGiff, J. C., N. A. Terragno, K. U. Malik, and A. J. Lonigro. 1972. Release of a prostaglandin E-like substance from canine kidney by bradykinin. Comparison with eledoisin. Circ. Res. 31:36-43.

37. Yun, J. C. H., J. R. Gill, F. C. Bartter, D. G. Kelly, and H. R. Keiser. 1982. Effect of bradykinin on renal function in dogs treated with indomethacin or propranolol. Renal Physiol. 5:31-43.

38. Tost, H., G. Kover, and K. Szemeredi. 1982. Study of the indomethacin and bradykinin antagonism in anaesthetized dogs. Acta Physiol. Acad. Sci. Hung. 59:131-139.

39. Garcia-Perez, A., and W. L. Smith. 1983. Apical-basolateral membrane asymmetry in canine collecting tubule cells: bradykinin, AVP, $\mathrm{PGE}_{2}$ interrelationships. Fed. Proc. 42:1259. (Abstr.)

40. Currie, M. G., B. R. Cole, K. DeSchryver-Kecskemeti, S. Holmberg, and P. Needleman. 1983. Cell culture of renal epithelium derived from rabbit microdissected cortical collecting tubules. Am. J. Physiol. 244:F724-F728.

41. Hial, V., H. R. Keiser, and J. J. Pisano. 1976. Origin and content of methionyl-lysyl-bradykinin, lysyl-bradykinin and bradykinin in human urine. Biochem. Pharmacol. 25:2499-2503.

42. Simson, J. A. V., S. S. Spicer, J. Chao, L. Grimm, and H. S. 
Margolius. 1979. Kallikrein localization in rodent salivary glands and kidney with the immunoglobulin-enzyme bridge technique. J. Histochem. Cytochem. 27:1567-1576.

43. Roblero, J., H. Croxatto, R. Garcia, J. Corthorn, and E. DeVito. 1976. Kallikreinlike activity in perfusates and urine of isolated rat kidneys. Am. J. Physiol. 231:1383-1389.

44. Yamada, K., and E. G. Erdos. 1982. Kallikrein and prekallikrein of the isolated basolateral membrane of rat kidney. Kidney Int. 22:331337.

45. Adetuyibi, A., and I. H. Mills. 1972. Relation between urinary kallikrein and renal function, hypertension, and excretion of sodium and water in man. Lancet. II:203-206.
46. Ueno, M., T. Kawasaki, K. Uezono, T. Omae, and M. Matsuoka. 1983. Relationship of urinary kallikrein excretion to renal water and sodium excretion. Metab. Clin. Exp. 32:433-437.

47. Arbeit, L. A. 1983. Endogenous kallikrein-kinin system modulates vasopressin action in the rat. Kidney Int. 23:272. (Abstr.)

48. Fejes-Toth, G., T. Zahajszky, and J. Filep. 1980. Effect of vasopressin on renal kallikrein excretion. Am. J. Physiol. 239:F388-F392.

49. Hulthen, U. L., J. F. Dymling, and B. Hokfelt. 1980. Kinins in relation to kallikrein activity, kininogen, electrolytes, aldosterone, and catecholamines in urine from normal individuals. Acta Physiol. Scand. 110:307-314. 